\title{
THE IMPACT OF TEACHING PHYSICAL \\ EDUCATION TO CZECH SCHOOL CHILDREN USING PROGRESSIVE TEACHING APPROACHES: FINDINGS OF A FOUR-YEAR STUDY
}

\author{
Karel Frömel ${ }^{1}$, Walid El Ansari², Jana Vašíčková ${ }^{1}$ \\ ${ }^{1}$ Faculty of Physical Culture, Palacky University, Olomouc, Czech Republic \\ ${ }^{2}$ Faculty of Sport, Health and Social Care, University of Gloucestershire, Gloucester, United Kingdom
}

\begin{abstract}
SUMMARY
Practice teaching is an important feature of pre-professional preparation of teachers. This study assessed student teachers' (STS) and pupils': overall evaluation and evaluation of pupils' roles in physical education (PE) and second subject lessons. STs delivered the lessons using either traditional or progressive teaching approaches. Questionnaires were completed by 57 STs and 10,517 high school pupils who assessed the lessons taught by the STs. Differences in the evaluation of pupil's role were analysed according to teaching approach, school years, and gender. In both types of lessons, pupils evaluated progressive teaching approaches more positively than the traditional approaches. Pupils' roles in lessons delivered using progressive teaching approaches also increased. STs evaluated the progressive approaches in both lessons more positively than traditional approaches. Girls evaluated PE lessons more favourably than boys regardless of teaching approach. If the goal is to increase pupils' role in the lessons, progressive teaching approach may be more effective than traditional.
\end{abstract}

Key words: student teacher, teaching style, high school pupils, gender, questionnaire, health

Address for correspondence: J. Vašíčková, Faculty of Physical Culture, Palacky University, Tř. Míru 115, 77111 Olomouc, Czech Republic. E-mail: jana.vasickova@upol.cz

\section{INTRODUCTION}

During the pre-professional preparation of teachers, student practice teaching experience provides undergraduate students teachers (STs) the opportunities to work and communicate with pupils in various school environments (1). STs' practice experience enhances the collaboration between elementary and secondary schools on the one hand (where teaching happens), and universities on the other (where teacher training happens) (2). Pre-professional preparation also provides STs with opportunities to efficiently work together with teachers who supervise the classes. Such interactions assist in the translation of research findings into practice, and instil evidence-based procedures that enhance the educational experience. Furthermore, practice teaching sessions are opportunities where new instructional approaches are implemented and tested (3).

Student practice teaching where STs acquire teaching and management skills (e.g. in PE lessons) is a useful formative evaluative tool to formulate optimal structure and content of STs' pre-professional curriculum $(1,4)$. This is important, as although the preparation of future PE teachers necessitates early explorations of every aspect of the 'real' world of PE teaching, recent analyses of practice teaching suggested several shortfalls (5-7). Other challenges in teacher development include the extent of teachers' respect for pupil's emotions, as well as their predictions about the skill levels of pupils (8). Hence there has been calls that "shaping the future of the nation's work force in
PE may start with early induction into teaching, in addition to a longer student teaching period" (1). The focus would be twofold: to improve STs' skills in enhancing the pupils' involvement in the educational processes; and to boost STs' abilities and fluency in progressive interdisciplinary teaching.

Globally, current educational systems emphasise the greater involvement of pupils in the educational processes. This includes freedom in decision making, independence, creativity, as well as self-diagnosis and self-evaluation (9). In PE, further aims are to increase pupils' enjoyment during physical activity, and their responsibility for success (10-12). When pupils participate in decisions on their activities (13-14), their motivation increases and they do not have reasons to misbehave (15).

\section{Progressive Interdisciplinary (Cross-curricular) Teaching}

Interdisciplinary (cross-curricular) teaching involves conscious efforts to apply knowledge, principles, and values to more than one academic discipline simultaneously. The disciplines may be related through a central theme, issue, problem, process, topic, or experience (16). However, little research has investigated progressive approaches that apply interdisciplinary teaching integration in order to enhance STs' pedagogical knowledge, and boost pupils' role in the educational experience (17). In the U.S.A, studies examined the interdisciplinary integration of $\mathrm{PE}$ with languages (18-19), PE with literature (20), PE with mathematics skills (21), PE with science (22), and PE with art (23). However, no previous research explored these issues in school populations in the Czech 
Republic. In addition, previous studies employed questionnaires to measure only the pupils' views during ST practice teaching (24-25) in order to compare different teaching styles (26) or various aspects of teaching PE. Hence to the best of our knowledge, the simultaneous assessment and comparison of both STs and pupils views of traditional and progressive teaching styles has not been previously undertaken. Further, in the research described in this paper, other subject/s that form part of STs's major (i.e. the second approbation subject, see below) were not taught through $\mathrm{PE}$, rather both subjects ( $\mathrm{PE}$ and second approbation subject) were employed to tackle the same challenge of increasing the pupils' role during learning, as STs delivered the knowledge applying progressive teaching style in both subjects.

Intervention: Progressive Interdisciplinary Teaching to Increase Pupils' Involvement in the Educational Experience

Teacher education study programmes in the Czech Republic consist of two different majors. For the programme described in this paper, the first major was $\mathrm{PE}$, and students were able to choose their second major (second subject - SS) from 11 different subjects (e.g. math, history, geography, etc.). The present study mobilized STs' pedagogical knowledge through a progressive teaching style characterized by an increased pupil's role in the lessons of both subjects (PE and SS). This progressive style comprised 11 features as described by others (27), and we focused mainly on some features: e.g. teacher as guide to the educational experience; active pupil roles; co-operative group work; and emphasis on creative expression. Conversely, traditional teaching style in the present study refers to some attributes: teacher as knowledge distributor; passive pupil roles; high emphasis on memory, practice and competition; and, little emphasis on creative expression. We compared the progressive style with the traditional teaching style in both subject lessons (PE and SS).

The study objectives were to assess five features in relation to STs' use of progressive and traditional teaching styles for both the $\mathrm{PE}$ and SS lessons. Two measures were computed from the pupils' questionnaires: pupils' overall evaluation (all 24 questions); and the evaluation of pupil's role (subset of 8 questions). The five specific objectives were:

As regards pupils:

- Was pupils' overall evaluation of the lessons and evaluation of their perceived role more positive regarding the progressive teaching approaches compared with the traditional approach?

- Was pupils' evaluation of their roles in lessons with different teaching approaches associated with their gender?

- Was pupils' overall evaluation of the lessons and evaluation of their perceived role more positive regarding the progressive teaching approaches compared with the traditional approach across the four years of the study?

As regards STs:

- Were STs' progressive teaching styles associated with increased pupils' roles in the lessons?

- Did STs evaluate positively their use of progressive teaching styles in the lessons (quantitatively)? What comments did STs have about applying progressive teaching (open comments section)?

\section{METHOD}

\section{Setting}

STs attending PE teacher education study programmes in Czech universities go through 2 three-week continuous practical teaching at schools of their choice. Initially, they observe PE and SS lessons while the lessons are being taught by the teachers. Later, they teach lessons pertaining to both their majors. STs' initial practice teaching takes place in spring (4th year of their study programme), where they learn, listen, and observe how to teach for half of their time at school. Then, they become professionally involved in the second practice teaching in autumn (5th year of their study programme).

\section{Participants}

Fifty seven STs (31 females, 26 males) studying PE and SS in three different universities in the Czech Republic (Moravia region - Olomouc, Ostrava, and Brno) participated in the study. The research was undertaken during the STs' second practice teaching block in autumn (5th year of their study programme). Data were collected every second school year during autumn practice teaching years, where the percentage of total number of questionnaires collected from pupils was 2001/2002 - 30.6\%; 2003/2004 -32.7\%; 2005/2006-17.7\%; 2007/2008-19\%. The pupil sample comprised 5,299 pupils who evaluated the traditional lessons and were compared to 5,218 pupils who evaluated the progressive lessons. They were the same pupils as they completed pairs of questionnaires for the different teaching approaches (traditional and progressive) of each lesson (PE and SS).

The schools where STs carried out their practice teaching were selected based on previous collaborations between the participating universities and the schools, mostly located in the Moravia region. All teachers who supervised the classes were qualified full-time pedagogically skilled teachers ( $>5$ years teaching experience). Across the participating schools, the principals / supervising teachers approved the study, and participation was voluntary and anonymous. Pupils and STs completed the questionnaires directly after any given lesson (required $\approx 5$ minutes), and there was space on the second page of the questionnaire for commentary that participants wished to add.

\section{Procedures}

STs'teaching assignments. As part of the study every participating ST taught one lesson using a traditional approach (traditional lesson) and another lesson using the progressive approach (progressive lesson) in each of the two subjects (PE/SS). Each lesson's content depended on the ST, the supervising teacher and school curriculum. Traditional lesson refers to the commonly used, typical, and traditional teaching style applied (STs taught as they were used to and in the manner that suited them). The progressive lesson had same structure and content as the traditional lesson, however, STs had to significantly increase the pupil's role in the different (diagnostic, cognitive, behavioural, evaluative, and motivational) components of educational process. For pupils, this meant more independence, self-diagnostics, self-evaluation, creativity, cooperation, sharing the leadership role, and other activities that enforce pupil's role in the educational process. 
All STs were trained in advance by the research team. The training comprised two sessions on peer teaching strategies, cooperative learning, self-instruction teaching and indirect instruction teaching (28). In addition, STs could use a spectrum of Mosston's teaching styles (29), particularly those that increase the pupil's role. These included productive teaching styles (guided discovery, convergent discovery, divergent production, individual program-learner design, learner-initiated, self-teaching), and reproductive teaching styles (command, practice, reciprocal, self-check, inclusion teaching styles), as shifts in the pupil's role are achieved using such styles (30). All STs received examples of lesson plans for the progressive $\mathrm{PE} / \mathrm{SS}$ lessons and algorithms to modify commonly used exercises and games in their school settings. The training did not aim to make all STs use exactly the same teaching styles in their practice teaching, rather it demonstrated the many possibilities that existed and encouraged STs to use their knowledge independently. Hence the content and instruction in the taught lessons were left to the STs and the teaching assignment of the teacher who was supervising any given lesson. STs who had taught at least one traditional PE/ SS and one progressive PE/SS lesson participated in the study by completing the questionnaire directly after a traditional lesson and again after a progressive lesson. They also provided corresponding lesson plans to their University mentor responsible for the teaching practice to: show the type of progressive teaching intervention that the ST implemented; and served to document the teaching that was delivered and how STs taught.

Questionnaires. For the PE lessons, the pupil questionnaire and the ST questionnaire each included 24 identical questions (adapted to either pupils or STs). Pupils were also asked to rate their perceived performance in class relative to their classmates. A slightly modified questionnaire evaluated the SS lessons, comprising 20 original items and 4 slightly modified questions that addressed the given SS under study.

The questionnaire was adapted from published sources (3132). The opening items inquired about school, class, gender, and self reported performance within the class. All 24 questions had 'YES/NO' response format and addressed six aspects (cognitive, emotional, health, interaction, relation, and creativity - 4 questions each). In addition, questions 2, 4, 6, 12, 16, 18, 19, and 22 were scored separately as a measure of the pupil's perceived role. These are important aspects to study when examining pupil's involvement (31-34). A total score for each questionnaire was derived by tallying the number of positive answers to questions 1 through 9, 12 through 16, 19 through 22, and 24; and the number of negative answers to questions $10,11,17,18$, and 23. Splithalf reliability coefficients as reported by Frömel et al. (31) were excellent (0.82 - pupil's questionnaire total score; 0.92 - pupil's role subscale).

Statistical analysis. Descriptive analyses were conducted separately for the PE and SS lessons using STATISTICA 6.0 software. Kruskal-Wallis ANOVA compared pupils' responses to traditional and progressive lessons. Data were not normally distributed, pupil's questionnaires were anonymous and so we used ANOVA for independent samples. Effect size was estimated using $\eta^{2}$ (35). Friedman's ANOVA compared responses from STs' questionnaires. Their questionnaires were not anonymous and thus could be paired, so we used Friedman's ANOVA for repeated measures. We also analyzed STs' open comments on the lessons they delivered, categorizing them into positive and negative commentary.

\section{RESULTS}

Traditional lessons pupils completed 5,299 questionnaires (PE lessons: 2,917 questionnaires - 1,812 girls, 1,105 boys; SS lessons: 2,382 questionnaires - 1,319 girls, 1,063 boys). Progressive lessons pupils completed 5,218 questionnaires (PE lessons: 2,872 questionnaires - 1,775 girls, 1,097 boys; SS lessons 2,346 questionnaires - 1,282 girls, 1,064 boys). Analysis of the participating pupils by the SS lesson subject included: Biology (24.2\%), Geography (22.9\%), Maths (17.5\%), Social Studies (8.2\%), Czech Language (7.3\%), German Language (4.1\%), English (3.8\%), Technical Education (3.0\%), Art Education (3.0\%), Spanish (2.6\%), Chemistry (1.3\%), and others (2.1\%).

Was pupils'overall evaluation of the lessons and evaluation of their perceived role more positive regarding the progressive teaching approaches as compared with the traditional approach?

Section A of Table 1 shows the results from pupils' questionnaires across all four years (the whole duration of the study) and also for individual academic years. A maximum point for overall evaluation was 24, for pupil's role 8 . On average, for both PE and SS, pupils who attended the progressive lessons reported more favourable overall evaluation of the lessons than pupils in the traditional lessons. However, $\eta^{2}$ estimates were low.

As regards pupil's role, pupils evaluating the progressive PE and SS lessons felt their role as more significant than in the traditional lessons. This was true for all four years (the whole duration of the study) and also for individual academic years (Table 1, Section B). E.g. in PE (question 6- "Did you have a chance to solve a problem on your own?”), $64 \%$ of pupils in the progressive lessons responded positively (46\% in the traditional lessons). In the SS for the same question, $84 \%$ of pupils felt positive in the progressive lessons (64\% in the traditional lessons). Similarly, in PE (question 12 - "Did you have a chance to make a decision in the lesson to do something on your own and in your own way?”), $79 \%$ of progressive lesson pupils responded positively (62\% in the traditional lessons). In the SS for the same question, 77\% of progressive lesson pupils reported favourably (63\% in the traditional lessons).

Was pupils' evaluation of their role in lessons with different teaching approaches associated with their gender?

In connection with gender, girls evaluated all lessons more positively than boys (Table 2). As regards PE lessons, the differences were significant both in traditional lessons and progressive lessons. Girls also evaluated the pupil's role more positively than boys in traditional lessons as well as in progressive lessons. However, as regards SS lessons, the decrease between girls' and boys' overall evaluations was significant only in progressive lessons. Girls reported pupil's role more positively in progressive SS lessons, but boys reported it more positively in traditional SS lessons.

Was pupils' overall evaluation of the lessons and evaluation of their perceived role more positive regarding the progressive teaching approaches compared with the traditional approach across the four years of the study? 


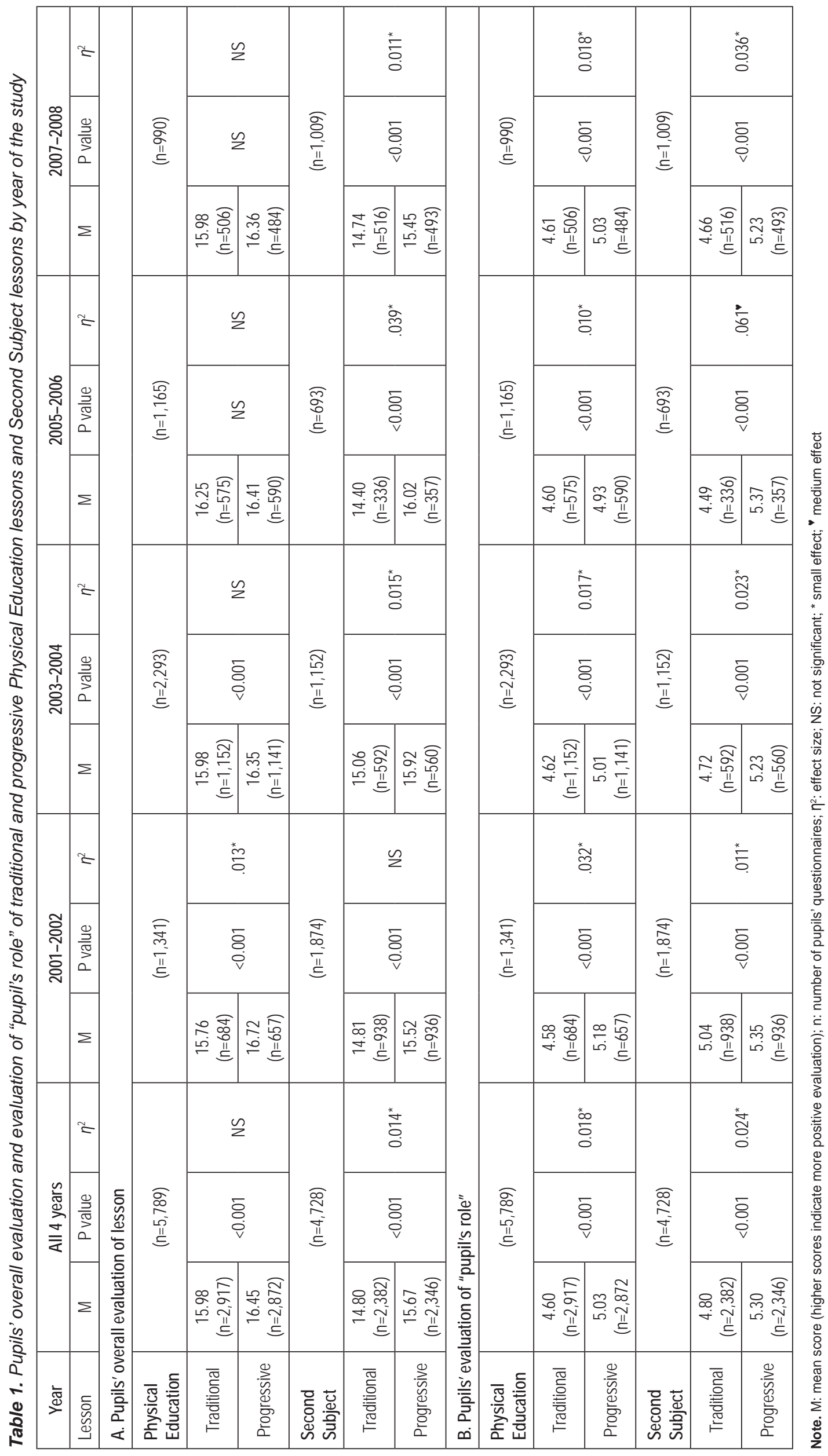


Table 2. Pupils' overall evaluation and evaluation of "pupil's role" of traditional and progressive Physical Education lessons and Second Subject lessons by gender

\begin{tabular}{|c|c|c|c|c|c|}
\hline \multirow{2}{*}{\multicolumn{2}{|c|}{ Lesson }} & \multicolumn{2}{|c|}{$M(n)$} & \multirow{2}{*}{$P$ value } & \multirow{2}{*}{$\eta^{2}$} \\
\hline & & Girls & Boys & & \\
\hline \multicolumn{6}{|c|}{ A. Pupils' overall evaluation of lesson } \\
\hline \multicolumn{6}{|c|}{ Physical Education } \\
\hline & Traditional & $16.50(1,812)$ & $15.13(1,105)$ & $<0.001$ & $.023^{*}$ \\
\hline & Progressive & $17.06(1,775)$ & $15.45(1,097)$ & $<0.001$ & $.029^{*}$ \\
\hline \multicolumn{6}{|c|}{ Second Subject } \\
\hline & Traditional & $14.83(1,319)$ & $14.77(1,063)$ & NS & NS \\
\hline & Progressive & $15.97(1,282)$ & $15.32(1,064)$ & 0.002 & NS \\
\hline \multicolumn{6}{|c|}{ B. Pupils' evaluation of "pupil's role" } \\
\hline \multicolumn{6}{|c|}{ Physical Education } \\
\hline & Traditional & $4.74(1,812)$ & $4.38(1,105)$ & $<0.001$ & NS \\
\hline & Progressive & $5.22(1,775)$ & $4.72(1,097)$ & $<0.001$ & $.019 *$ \\
\hline \multicolumn{6}{|c|}{ Second Subject } \\
\hline & Traditional & $4.73(1,319)$ & $4.89(1,063)$ & 0.017 & NS \\
\hline & Progressive & $5.40(1,282)$ & $5.18(1,064)$ & 0.013 & NS \\
\hline
\end{tabular}

Note. M: mean score (higher scores indicate more positive evaluation); n: number of pupils' questionnaires; $\eta^{2}$ : effect size; NS: not significant; * small effect

Table 3. Student teachers overall evaluation and evaluation of "pupil's role" of traditional and progressive Physical Education lessons and Second Subject lessons

\begin{tabular}{|c|c|c|c|c|}
\hline Lesson & & M & $P$ value & $\eta^{2}$ \\
\hline \multicolumn{5}{|c|}{ A. Student Teacher overall evaluation of lesson } \\
\hline \multicolumn{5}{|c|}{ Physical Education } \\
\hline & Traditional $(n=57)$ & 16.49 & $<0.001$ & $0.504^{* *}$ \\
\hline & Progressive $(n=57)$ & 18.56 & & \\
\hline \multicolumn{5}{|c|}{ Second Subject } \\
\hline & Traditional $(n=55)$ & 15.87 & $<0.001$ & $0.505^{\star \star}$ \\
\hline & Progressive $(n=55)$ & 17.71 & & \\
\hline \multicolumn{5}{|c|}{ B. Student Teacher evaluation of "pupil's role" } \\
\hline \multicolumn{5}{|c|}{ Physical Education } \\
\hline & Traditional (n=57) & 4.86 & $<0.001$ & $0.210^{* *}$ \\
\hline & Progressive $(n=57)$ & 6.79 & & \\
\hline \multicolumn{5}{|c|}{ Second Subject } \\
\hline & Traditional $(n=55)$ & 5.51 & $<0.001$ & $0.172^{\star \star}$ \\
\hline & Progressive $(n=55)$ & 6.67 & & \\
\hline
\end{tabular}

Note. M: mean score (higher scores indicate more positive evaluation); n: number of student teachers' questionnaires; $\eta^{2}$ : effect size; ** big effect

Table 1 indicates that across four school years of the study progressive teaching approaches were evaluated more positively than the traditional approach with effect sizes varying from 0.010 to 0.061 . The two exceptions were pupils' overall evaluation of PE lessons in 2005/2006 and 2007/2008.

Were STs'progressive teaching styles associated with increased pupils' roles in the lessons?

In PE lessons as well as SS lessons, STs reported that the pupil's role increased in connection with the progressive teaching style (Table 3, Section B).
Did STs evaluate positively the progressive teaching styles in the lessons (quantitatively)? What comments STs had about applying progressive teaching styles (open comments section)?

As the case of the pupils, STs evaluated the progressive lessons in both PE and SS lessons (section A, Table 3) more positively than the traditional lessons. Qualitative data (from the open comments section of the questionnaire) indicated that about 30\% of STs felt that their pre-professional preparation was insufficient, reporting the need for a better understanding of individualization, creativity and cooperation. STs perceived that they lacked experience and 
Box 1. Student teachers' positive comments and perceived challenges of progressive PE lessons

\begin{tabular}{|l|}
\hline Positive comments \\
\hline Self-importance and feeling of success increased; Pupils liked it more- they developed an interest to cooperate; They (pupils) worked harder and had fun, too; \\
They (pupils) cooperated well because they did new things; they could vary their activities; They (pupils) were trying to develop something new \\
\hline Perceived challenges \\
\hline $\begin{array}{l}\text { Pupils were surprised that they can choose the exercise but then they enjoyed it. Later they had no other ideas and the enjoyment was gone; Pupils always } \\
\text { expected my instructions; Pupils expect the same lesson organization; Because of the higher freedom in decision making, pupils could not keep their attention. } \\
\text { I always had to solve conflict between pupils; Some pupils didn't want to think and create anything new; Some pupils abused the freedom and they avoided learn- } \\
\text { ing in this environment; I had problems with active pupils who were working all the time and with less active pupils who organized small, less active groups }\end{array}$ \\
\hline
\end{tabular}

that there more time could have been spent on methodological problems (e.g. how to deal with misbehaviour, how to better organise gym setting or how to control pupils sufficiently). Participants stated that "We have theoretical knowledge but we are not able to use it" and "I would have liked a practical demonstration of a recommended progressive PE lesson in pre-professional preparation. Practice is more difficult than theory."

There were no expressed negative comments about the success of progressive lessons. This suggested that most instructional problems in the progressive lessons could have been created by pupils' misbehaviour (20\% of STs), insufficient preparation, and lack of experience (37\% of STs). Positive comments suggested the increase in pupils' interest and motivation; a better work atmosphere; and better communication: "I like that we could communicate more with pupils.” No STs reported absolute dissatisfaction with the progressive lessons. Box 1 shows some positive comments and some perceived challenges of progressive teaching styles.

Most STs evaluated the supervising teacher positively. For example: "My supervising teacher welcomed the progressive lessons, she evaluated them as a good idea. I think she will use them in her teaching style, too." Other comments included: "The teacher let me work my way and always helped me and participated in the exercises, too"; "She said that she doesn't use that [progressive] teaching method, but she would like to try it.” About $13 \%$ of STs expressed challenges as regards the supervising teacher in the progressive lessons: "The teacher had a tendency to direct the lesson and pupils according to her ideas”; “According to the supervising teacher, the pupils' misbehaviour is the reason why she would not use the progressive lesson"; and "The teacher let me teach the progressive lesson but didn't help me with anything."

\section{DISCUSSION}

Student teaching is an important area of undergraduate teacher preparation (1) where STs experience first-hand working with pupils to apply different teaching methodologies. The feedback STs receive is complex and variable and is one of the many requirements for effective professional preparation (36).

As regards the first objective, pupil's evaluations of the traditional and progressive lessons in PE and SS were overall positive. Futhermore the progressive teachig approach did not cause an extra health burden on the pupils. This suggested that pedagogical influence to increase pupil's role in progressive lessons was worthy. In our study, pupils were positively influenced by the progressive teaching approaches even though the teaching was undertaken by different STs and within different school settings (secondary/ grammar/ vocational schools with different material equipment). Progressive teaching approaches were regarded as new, challenging and source of instant enjoyment, qualities that according to researches (37) are considered as major components of interest in physical activities.

Regarding the second objective, overall females evaluated PE lessons more positively than males, in agreement with previous work (31). Czech females usually accept new approaches and possibilities to participate in the organisation and leadership of $\mathrm{PE}$ lesson with less criticism. Our findings are in contrast with others (38) in Germany, where females in Grades 5 and 9 evaluated quality of PE lessons more critically than males. Similarly, other authors (39) examined attitudes toward PE in high school students in four countries (Austria, England, USA, and Czech Republic). They found gender difference in attitude to PE, where males scored significantly higher than girls. But analysis of individual countries revealed that males had better attitudes toward PE than females with the exception of the Czech Republic, which supports our gender findings. Whilst country differences might be explained by structural factors e.g. course requirements specific to the Czech Republic, curriculum content, student-to-teacher ratios, and the level of importance attached to PE by educators, however, the reasons for gender differences invite further research.

As for the third objective, in school years 2005/2006 and 2007/2008 we did not find significant differences in pupils' overall evaluation of PE lessons with traditional and progressive teaching approach while in SS lessons progressive teaching approach was evaluated more positively in all four school years. As we presented the findings from the questionnaires of the PE lessons in school years 2001/2002 and 2003/2004 during STs preprofessional preparation, it might have been one of the reasons for insignificant differences.

As for the fourth objective, the increase and diversity of the pupil's roles was higher in the progressive approach compared to the traditional lesson in both PE and SS approach. This suggested that STs were able to use the newly acquired teaching strategies (28) and teaching styles (29) to increase the pupil's role successfully.

Finally in relation to objective five, although STs evaluated positively the progressive approaches in both PE and SS lessons, pupil misbehaviours were marginally more in progressive lessons than in traditional lessons. However, the slight increase in pupils' misbehaviour was not reported by STs as a serious problem.

The comments on progressive teaching styles highlighted the challenges encountered by STs' in relation to classroom manage- 
ment (groups of pupils) and lesson plan implementation (problems with keeping pupils' attention all the time). Such challenges with STs' preparedness to teach and their ability to manage a class were highlighted by others (40) based on PE teaching practice experiences in Singapore, UK and USA. Although STs should have had obtained sufficient content and pedagogical knowledge as part of their undergraduate study, some STs expressed feelings that their pedagogical knowledge was not satisfactory. Some comments also suggested that some STs were not quite ready for their teaching profession. This notion was supported by $30 \%$ of the STs who thought that their pre-professional preparation was insufficient.

Some STs felt that pupils were not used to choosing on their own and that was a reason why this type of teaching required more management time in terms of class organization. Further, the Czech education system has a traditional tendency to keep pupils well disciplined, especially in PE lessons. The challenge is the fine balance and tradeoffs between the necessary level of discipline and the sharing role of pupils in the educational process. It may be that the "more time in class organization" that is required may decrease the level of pupils' dissatisfaction with physical activity. Previous studies suggested that a different than traditional approach to education does not decrease level of pupils' physical activity (31-33).

The strengths of this study include that each ST used the same teaching methodology for both the PE and SS lessons (slightly modified according to school subjects). This might be very helpful especially for countries with a two-subject study program for teachers at universities (PE combined with SS). Similarly, the use of the same evaluative instruments (questionnaires that were very similar, containing cognate questions and evaluative aspects) that differed only in addressing either educators or learners so that we could obtain two different viewpoints that were collected immediately after any given lesson. Such research has not been undertaken to date in any country. Limitations include that we carried out research only in one region of the Czech Republic; we did not study STs' previous experience in working with children; and pupils met these STs for the first time (novelty) during their practice teaching which might influence positively or negatively pupils' attitude to the lessons. We did not document the content of the PE lessons, and that may have significantly influenced the attitude of pupils because girls prefer aesthetically oriented activities and boys incline rather to fitness activities (41).

For comparative purposes future research should examine whether the findings of this study are replicated in different schools, and different countries, with use of more complex experimental techniques, and more qualitative methods.

\section{CONCLUSIONS}

Practice teaching is an effective (and economical) method to influence positively the praxis at schools. Progressive lessons aim to increase "pupils' role" (self-actualization, self-assertion, higher responsibility) in the educational process and it was shown to be successful in PE and in SS lessons. Both STs and pupils evaluated progressive PE and SS lessons more positively than traditional lessons. Integration of progressive approaches into different lessons and different subjects can be an excellent platform for not only effective cross-teaching integration but also for thematic unit integration which more closely connects school programs with common life. It can also offer wider employment of pre-service teachers by broadening their divergent thinking and improving their quality as well-prepared PE teachers.

\section{Acknowledgments}

The study has been supported by the research grant from the Ministry of Education, Youth and Sports of the Czech Republic (No. MSM 6198959221) "Physical Activity and Inactivity of the Inhabitants of the Czech Republic in the Context of Behavioral Changes".

We wish to express our thanks Dr. Zbyněk Svozil (FTK UP) who helped with organisation of the research, and František Chmelík, Ph.D. (FTK UP) who contributed constructive comments on earlier draft of this manuscript.

\section{REFERENCES}

1. Chepyator-Thomson JR, Liu W. 'Pre-service teachers' reflections on student teaching experiences: lessons learned and suggestions for reform in PETE programs. Phys Educator. 2003 Mar 22;60(2):2-12.

2. Wirszyla C. State-mandated curriculum change in three high school physical education programs. J Teach Phys Educ. 2002 Oct;22(1):4-19.

3. Chen W, Cone T. Links between children's use of critical thinking and an expert teacher's teaching in creative dance. J Teach Phys Educ. 2003 Jan;22(2):169-85.

4. Siedentop D. Content knowledge for physical education. J Teach Phys Educ. 2002 July;21(4):368-77.

5. Chmelík F, Frömel K, Svozil Z. Student teacher ability to apply progressive intervention in both their majors during teaching practice. Acta Univ Palacki Olomuc Gymn. 2007;37(4):31-6.

6. Graber KC. The influence of teacher education programs on the beliefs of student teachers: general pedagogical knowledge, pedagogical content knowledge, and teacher education course work. J Teach Phys Educ. 1995 Jan;14(2):157-78.

7. Chen K, Tan J, Khoo A. Pre-service teachers' conceptions about teaching and learning: a closer look at Singapore cultural context. Asia Pac J Teach Educ. 2007 May;35(2):181-95.

8. McCaughtry N, Rovegno I. Development of pedagogical content knowledge: moving from blaming students to predicting skillfulness, recognizing motor development, and understanding emotion. J Teach Phys Educ. 2003 July;22(4):355-68.

9. Penney D, Chandler T. Physical education: what future(s)? Sport Educ Soc. 2000 Mar;5(1):71-87.

10. LaMaster KJ. Enhancing preservice teachers' field experiences through the addition of an early field experience component. J Exp Educ. 2001;24(1):27-33.

11. Treasure DC, Roberts GC. Students' perceptions of the motivational climate, achievement beliefs, and satisfaction in physical education. Res Q Exerc Sport. 2001 Jun;72(2):165-75.

12. Ussher B, Gibbes C. Vygotsky, physical education and social interaction. J Phys Educ New Zeal. 2002 Jul;35(1):76-86.

13. Cuddihy TF, Corbin CB, Dale D. A short instrument for assessing intrinsic motivation for physical activity. Phys Educator. 2002;59(1):26-37.

14. Mandigo JL, Holt NL. Putting theory into practice: how cognitive evaluation theory can help us motivate children in physical activity environments. J Phys Educ Recr Dance. 2000 Jan;77(1):44-9.

15. Boyce A. Inappropriate student behavior - a problem for student teachers. J Phys Educ Recr Dance. 1997 Aug;68(6):28-30.

16. Houghton Mifflin Company [homepage on the Internet]. What is interdisciplinary/cross-curricular teaching? [cited 2008 Oct 21]. Available from: http://www.eduplace.com/rdg/res/literacy/interd0.html.

17. Carlson TB, McKenna P. A reflective adventure for student teachers. J Exp Educ. 2000 Jun;23(1):17-25.

18. Bell ND, Lorenzi D. Facilitating second language acquisition in elementary and secondary physical education classes. J Phys Educ Recr Dance. 2004 Aug;75(6):46-51.

19. Clancy ME, Hruska BL. Developing language objectives for English learners in physical education lessons. J Phys Educ Recr Dance. 2005 Apr;76(4):30-5.

20. Stringer S, Reilly E. Literature circles in the physical education classroom. Strategies. 2004 Mar/Apr;17(4):35-7. 
21. Casas B, DeFrancesco C. Elementary physical education and math skills development. Strategies. 2004 Nov/Dec;18(2):21-3.

22. Buchanan AM, Martin E, Childress R, Howard C, Williams L, Bedsole B, et al. (2002) Integrating elementary physical education and science: a cooperative problem-solving approach. J Phys Educ Recr Dance. 2002 Feb;73(2):31-6.

23. Altman SR, Lehr CA. Integrating sport, physical activity, and the arts in education. Strategies. 2003 Mar/Apr;16(4):15-8.

24. Mitáš J, Frömel K. Social and relational interactions in different types of PE lessons during student teachers' practice teaching. Acta Univ Palacki Olomuc Gymn. 2005;35(2):19-25.

25. Svozil Z, Vašendová J, Frömel K. Health dimension in physical education teaching units. In: Válková H, Hanelová Z, editors. Movement and health: supplement; 1999 Nov 14-17. Olomouc: Palacky University; 1999. p. 489-92.

26. Vašíčková J. Individualized instruction in school physical education [unpublished dissertation]. Olomouc: Palacky University; 2002. (In Czech.)

27. Francis LJ, Grindle Z. Whatever happened to progressive education? A comparison of primary school teachers' attitudes in 1982 and 1996. Educ Studies. 1998 Nov;24(3):269-79.

28. Bennett N. Teaching styles and pupil progress. 1st ed. London: Open Books; 1976

29. Mosston M, Ashworth S. Teaching physical education. 5th ed. San Francisco(CA): Benjamin Cummings; 2001

30. Byra M. A review of spectrum research: the contributions of two eras. Quest. 2000 Aug;52(3):229-45.

31. Frömel K, Vašendová J, Krapková J. Esthetic aspects of physical education classes for girls. Phys Educator. 2000;57(3):146-60.

32. Frömel K, Stratton G, Vašendová J, Pangrazi RP. Dance as a fitness activity: The impact of teaching style and dance form. J Phys Educ Recr Dance. 2002 May/Jun;73(5):26-30,54.
33. Frömel K, Lehnert M, Vašendová J. Volleyball for girls in school physical education. Int J Volley Res. 2000;2(1):30-4.

34. Svozil Z, Frömel K, Górna K. Individualisation in the professional preparation of the physical education teachers. Acta Univ Palacki Olomuc Gymn. 2002;32(1):27-36.

35. Morse DT. Minisize2: a computer program for determining effect size and minimum sample size for statistical significance for univariate, multivariate and nonparametric tests. Educ Psychol Meas. 1999 Jun;59(3):51831.

36. Wilson S, Williams JA. Student-created case studies for teacher education. J Phys Educ Recr Dance. 2001 Feb;72(2):49-53.

37. Subramaniam PR, Silverman S. Middle school students' attitudes toward physical education. Teach Teach Educ. 2007 July;23(5):602-11.

38. Rütten A, Ziemainz H, Abu-Omar K, Groth N. Residential area, physical education, and the health of school aged children. Health Educ. 2003;103(5):264-70.

39. Stelzer J, Ernest JM, Fenster MJ, Langford G. Attitudes toward physical education: a study of high school students from four countries - Austria, Czech Republic, England, and USA. Coll Student J [serial on the Internet]. 2004 Jun [cited 2008 Oct 24]. Available from: http://findarticles. com/p/articles/mi_m0FCR/is_2_38/ai_n6124562.

40. Wright $\mathrm{S}$. A comparative view of teaching practice in physical education. Int Sports Studies. 1999;21(1):55-68.

41. Frömel K, Formánková S, Sallis JF. Physical activity and sport preferences of 10 to 14-year-old children: a 5-year prospective study. Acta Univ Palacki Olomuc Gymn. 2002;32(1):11-5.

Received October 20, 2009 Accepted in revised form April 15, 2009 